\title{
Barrier and Sacrificial Protection Mechanisms of Zinc Rich Primers
}

\author{
Mohsen Saeedikhani $^{1, a}$, Sudesh L. Wijesinghe ${ }^{1,2, b}$, and Daniel John Blackwood ${ }^{1,, *}$ \\ 1 Department of Materials Science and Engineering, National University of Singapore, 9 Engineering Drive \\ 1, Singapore 117576, Singapore \\ 2 Measurements and Characterization Unit, Singapore Institute of Manufacturing Technology, A*STAR, \\ Singapore 138634, Singapore \\ E-mail: asaeedikhani@u.nus.edu, bsudeshw@simtech.a-star.edu.sg, cmsedjb@nus.edu.sg (Corresponding \\ author)
}

\begin{abstract}
A specific type of Zinc-Rich Primer was scratched and exposed in salt fog chamber for various exposure times up to 1,000 hours. The corrosion products that developed within the scratched region were studied by optical microscopy, scanning electron microscopy, and Electrochemical Impedance Spectroscopy. Bode plots were used to obtain the total resistance of the coating by salt spray exposure time. The results suggest that the mechanism of protection of zinc rich primer may not be simply as only sacrificial action followed by only barrier action, but rather an iteration of these two mechanisms exist. Although at very short times, prior to deposition of zinc corrosion products in the scratch, sacrificial action is the only mechanism of protection, once the corrosion products start to form there is a conjunction of the two protection actions with one dominating from time to time. This dual protection mechanism continues until all the available free zinc within the throwing power distance of the scratch has been consumed, at which point only barrier protection remains in action.
\end{abstract}

Keywords: Zinc Rich Paint, zinc corrosion product, sacrificial protection, barrier protection, salt fog test.

ENGINEERING JOURNAL Volume 23 Issue 4

Received 3 May 2019

Accepted 12 July 2019

Published 8 August 2019

Online at http://www.engj.org/

DOI:10.4186/ej.2019.23.4.223 


\section{Introduction}

Coating is applied to protect steel structures from corrosion effectively. The corrosion protection performance of a coating is highly influenced by its adhesion to the surface to which it is applied [1]. Corrosion as a spontaneous phenomenon has always been a major expense to many industries. Corrosion threatens industries' safety and is a prime factor in the failure of equipment. However, not all forms of corrosion are harmful and in fact, industries can sometimes benefit from corrosion phenomenon with the help of corrosion engineers. For instance, the mechanism of galvanic corrosion, which may occur once two dissimilar metals are electrically and electrolytically in contact with each other can be employed in order to protect certain metallic structures by means of sacrificial protective primers and coatings. In such, a more active metal is chosen as the coating's material in order to protect the underlying more noble substrate.

Among the different types of primer paints, zinc rich primers are the prime choice for use in corrosive environments, such as marine and industrial, due to their distinctive ability of protecting the substrate under slight mechanical damage $[1,4,5]$. Also, among all the sacrificial coatings, zinc based coatings have always been of most interest for the protection of steel substrates due to zinc's abundance, high electrochemical activity and its environmentally benign nature. Zinc coatings provide sacrificial protection, whilst regular paints form a moister resistant barrier between the substrate and the corrosive media.

Hence, different varieties of zinc coatings, from hot dip galvanized (HDG) coatings to zinc-rich paints, have been developed to tackle the corrosion of steel structures with the help of sacrificial protection. Hot dip galvanizing produces a layer of zinc metal on the steel base by immersing the steel in a kettle of molten zinc. Although HDG coatings provide superior corrosion resistant for the steel, it is limited to pieces that are small enough to be immersed in the kettle and cannot be applied onsite. Therefore, zinc rich paints (ZRPs) are preferred for larger structures, especially those that need to be assembled onsite, such as above ground oil tanks and pipelines in refineries. Note that the two prime components of ZRPs are the zinc dust and a binder, which may be organic or inorganic.

ZRPs are mainly composed of zinc dust (65-96\%wt. metallic zinc in dry film) mixed with organic or inorganic binders. The cathodic protection reactions initiate by corrosion of zinc $\left(\mathrm{Zn} \rightarrow \mathrm{Zn}^{2+}+2 \mathrm{e}\right)$ followed by transportation of the electrons to cathodic sites where react with oxygen and water to produce hydroxides $\left(\mathrm{O}_{2}+2 \mathrm{H}_{2} 0+4 \mathrm{e}^{-} \rightarrow 4(\mathrm{OH})^{-}\right)$and result in alkalization of the region - favorable for $\mathrm{Zn}(\mathrm{OH})_{2}$ formation $\left(\mathrm{Zn}^{2+}+2(\mathrm{OH})^{-} \rightarrow \mathrm{Zn}(\mathrm{OH})_{2}\right)$.

The significant anti-corrosive constituent in HDG and ZRP is zinc. The mass percentage of zinc on the dry film rates the life-time of such coatings. It is defined as mass per square meter to define life-time of the coating for HDG products. The zinc percentage in a ZRP coating is the percentage of zinc by weight on the dry film. Therefore, for the same thickness, the zinc mass per square meter for ZRP is lower than HDG.

However, various corrosion products will be developed in the damage region upon exposure to corrosive environment and by time [4-10]. Previous studies reported that zinc rich primers provide two primary protection mechanisms, namely sacrificial protection and barrier protection [4]. The active protection mechanism relies on the volume concentration of the zinc dust (pigment) in the primer. While the ratio of pigment volume concentration (PVC) to critical pigment volume concentration (CPVC) is below 1 (PVC/ CPVC < 1), barrier protection is in action. Galvanic protection will be governing when the primer is doped by higher ratios of PVC/ CPVC as an almost unbroken contact between zinc dust will be established [4]. The advantage of higher amounts of doped zinc in primer is more efficient galvanic protection of the substrate. However, in multilayer paint systems zinc corrosion products that extend to the substrate can cause delamination, due to the inducing lack of adhesion between the zinc rich primer, the substrate, and the top paint layer. Hence, study of the formation and the characterization of zinc paint corrosion products is fundamental for having a better vision on the protection mechanisms.

Electrochemical Impedance Spectroscopy (EIS) is a powerful technique for evaluation of the corrosion properties of paints and coatings [11-15]. EIS is a strong tool to study the performance and over-timedegradation of coatings [16, 17], although use of EIS for zinc rich paints could be misleading. For instance, some studies reported that for organic coatings a fall in the low-frequency impedance to less than $10^{-7}$ $\Omega . \mathrm{cm}^{2}$ indicates no longer protection [4], but this is deceptive for zinc primers as they are highly doped with conductive pigments and hence intrinsically have low resistances still they can protect the substrate excellently. Evidently, corrosion of the conductive pigments increases their electrical resistance as opposed to what has been reported for organic coating. 
In spite that numerous works to date have studied the corrosion protection mechanisms of zinc rich primers, the evolution of corrosion products in the damaged region and their part in protection of the substrate is still not well understood.

In this study, a one-layer zinc rich primer ( $96 \mathrm{wt} \%$ on the dry film) applied on ASTM 36 steel that has been scratched and exposed to salt spray was studied. Salt fog test as an accelerated corrosion test is a useful method to qualitatively compare the corrosion resistance of metals and coatings. Salt fog test could give useful and practical data about the protection ability of coatings against corrosion. Therefore, this test is one of the most well-established tests and hence was used in this study.

Optical microscopy and scanning electron microscopy were employed to visualize the morphologies of the corrosion products that evolved over time in the scratched region. Moreover, changes in the electrochemical behavior of the paint system was studied by EIS. All results are then used to expand the mechanisms of corrosion protection by ZRP.

\section{Materials and Methods}

ASTM A36 carbon steel was used as substrate with the dimension of $0.10 \mathrm{~m} \times 0.15 \mathrm{~m}$. The substrates were cleaned to white metal grade using blasting technique based on NACE No. 1 standard. The primer was applied using an airless spray by an applicator company. The primer was a commercial Zinc Rich Polymer (ZRP), $120 \times 10^{-6} \mathrm{~m}$ thick which contained $96 \mathrm{wt} \%$ zinc on dry film. The painted samples were kept in the ziploc bags in the dry cabinet before use. A scratching tool (1538 DIN) with the blade thickness of 500 $\times 10^{-6} \mathrm{~m}$ was used to apply a straight-line scratch through the coating. The length of the scratch was ca. 0.10 $\mathrm{m}$ and it went down to expose the substrate. In addition, the unwanted areas of the samples were insulated by a transparent sealing tape.

The scratched samples were exposed to a salt fog chamber and the test was conducted in accordance with ASTM B117. The salt fog exposure periods are reported in Table 1. The temperature of chamber was $35^{\circ} \mathrm{C}$. One unscratched sample was also exposed to salt fog for $1,000 \mathrm{~h}$ to compare the corrosion performance of the defect-free primer.

Table 1. The duration of salt fog based on ASTM B117.

\begin{tabular}{ll}
\hline Hours of exposure & Zinc Rich Polymer \\
\hline 2 & Scratched \\
\hline 6 & Scratched \\
\hline 24 & Scratched \\
\hline 48 & Scratched \\
\hline 96 & Scratched \\
\hline 168 & Scratched \\
\hline 240 & Scratched \\
\hline 780 & Scratched \\
\hline 1000 & Scratched \\
\hline 1000 & Scratched \\
\hline
\end{tabular}

After the samples were withdrawn from salt fog, they were rinsed with distilled water and instantly were undergone photography, and optical microscopy (Olympus MX51). Afterwards, to inspect the corrosion products through the cross section, the samples were cut by a precision cutter (Secotom 10) under extremely slow cutting speed machine. An epoxy resin was applied on the corrosion products at the scratch region and was let dry fully before cutting to avoid detachment of the corrosion products while cutting. The cross sections were examined by optical microcopy and SEM (Zeiss SUPRA 40). 
Finally, Gamry potentiostat (Interface 1,000) was used for open circuit potential (OCP) measurements and also to do EIS. EIS was carried out in an aqueous solution containing $3.5 \mathrm{wt} \% \mathrm{NaCl}$. Furthermore, the EIS cell was comprised of three electrodes, namely counter electrode, graphite electrode and Saturated calomel electrode (SCE) as the reference electrode. For EIS a sinusoidal voltage of $10 \mathrm{mV}$ root mean square with respect to OCP was applied. The frequency range was $100,000 \mathrm{~Hz}$ to $0.1 \mathrm{~Hz}$. The cell was obtained from Gamry known as Paint Cell. The tested area was set to $3 \times 10^{-4} \mathrm{~m}^{2}$ area using sample masks. Therefore, the area ratio of zinc paint over the scratch was almost 60 .

\section{Results and Discussion}

\subsection{Visual Inspection, Optical Microscopy, and Scanning Electron Microscopy}

The optical microscopy images in Fig. 1 show that zinc corrosion products increase by exposure time, this is more evident after $240 \mathrm{~h}$ which was due to the high zinc percentage in the primer.

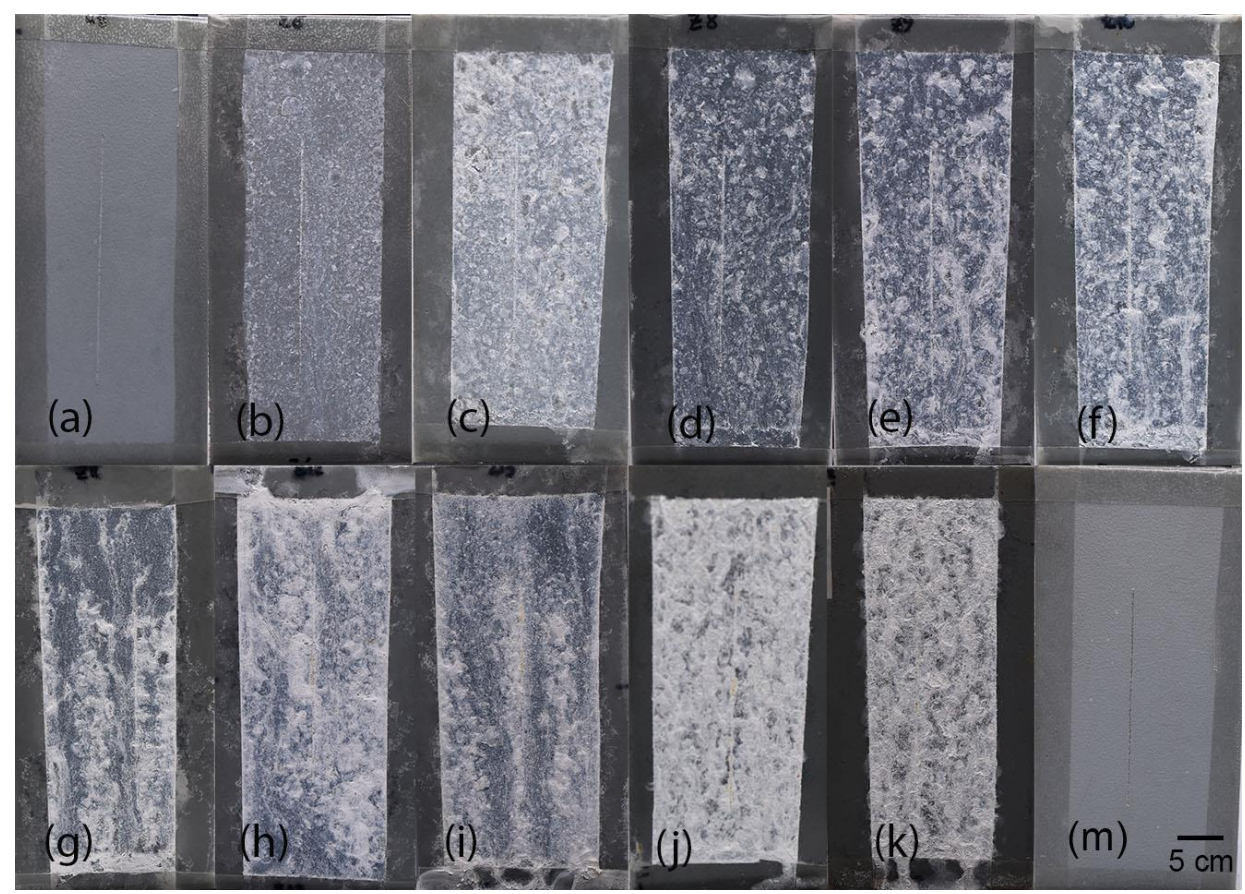

Fig. 1. Photography images of the samples after salt fog exposure for (a) $2 \mathrm{~h}$, (b) $6 \mathrm{~h}$ (c) $24 \mathrm{~h}$ (d) $48 \mathrm{~h}$, (e) $96 \mathrm{~h}$, (f) $168 \mathrm{~h},(\mathrm{~g}) 240 \mathrm{~h},(\mathrm{~h}) 480 \mathrm{~h}$, (i) $720 \mathrm{~h}$, (j) $1,000 \mathrm{~h}$, (k) 1,000 h unscratched, and (m) unscratchedunexposed.

Optical images shows that zinc corrosion products precipitate in the scratch gradually with corrosion time (Fig. 2). Zinc particles juxtaposed to the scratch corrode swiftly, and as a result, the corrosion products expand to the scratch region. Such corrosion products could cause barrier protection in the scratch if only they are not porous and adhere to the substrate. In addition, farther zinc particles from the scratch region will also contribute in sacrificial protection of the scratch so long as the throwing power of the paint allows to do so.

The local $\mathrm{pH}$ in the electrolyte could provide information on the local mechanisms. For instance, the presence of zinc hydroxide corresponds to the high $\mathrm{pH}$ regions, hence could be an implication of dominated sacrificial protection. Likewise, $\mathrm{pH}$ drop could imply that sacrificial protection becomes less dominant. In case $\mathrm{pH}$ of the electrolyte out of the scratch is acidic, zinc ions will be soluble, but can be transported into the scratch where the $\mathrm{pH}$ is mainly alkaline due to oxygen reduction reaction $\left(\mathrm{O}_{2}+2 \mathrm{H}_{2} \mathrm{O} \rightarrow\right.$ $\left.4(\mathrm{OH})^{-}\right)$. In alkaline regions soluble zinc ions could precipitate in terms of different zinc corrosion products and could form a protective layer.

The brown corrosion products in Figs. 2(h) and 2(i) are related to Fe corrosion products. They have appeared in the top view images after $480 \mathrm{~h}$ and after 1,000 h they are covered with white zinc corrosion 
products (Fig. 2(j)). Remark there is no trace of Fe corrosion products after 1,000 $\mathrm{h}$ for the unscratched sample (Fig. 2(k)).

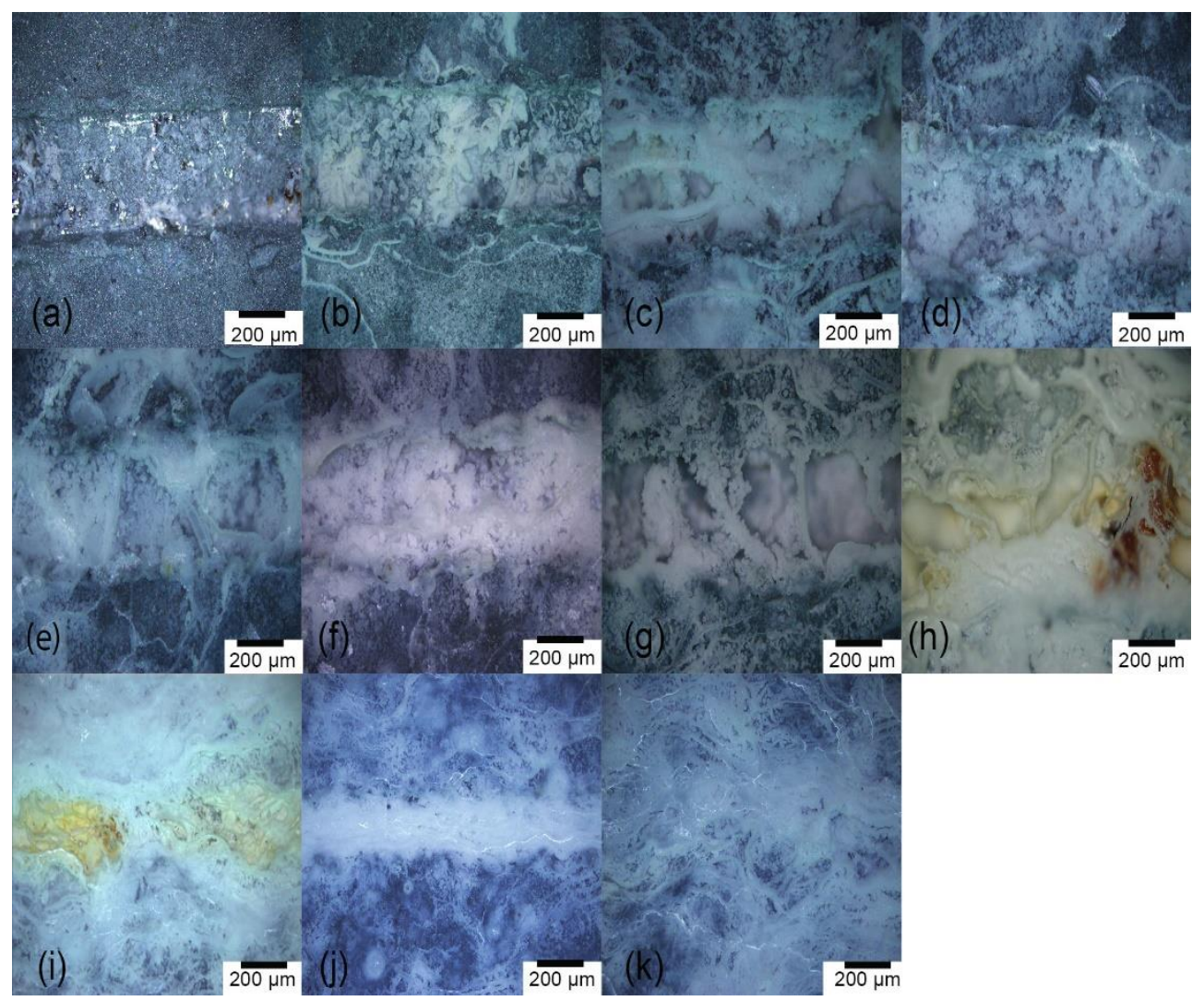

Fig. 2. Optical microscopy images of the top view of the samples for (a) 2, (b) 6 (c) 24 (d) 48, (e) 96, (f) 168, (g) 240, (h) 480, (i) 720, (j) 1,000, and (k) 1,000 unscratched hours in salt fog chamber.

Figure 3 depicts the samples from cross section. Figure 3 shows that zinc corrosion products have filled up in all the pits in the scratch. This mechanism could postpone iron corrosion by impeding the growth of pit for a certain amount of time.

Furthermore, Fig. 3 shows that the majority of corrosion products are formed at the middle of the scratch. These middle-precipitated corrosion products are likely to be mostly $\mathrm{Zn}(\mathrm{OH})_{2}$ and $\mathrm{ZnO}$ which are stable in alkaline ranges. Oxygen reduction will continue to occur in the middle of the scratch region, which leads to further formation and accumulation of corrosion products over this region. Accumulation of the corrosion products will not lead to a full insulating barrier, as corrosion products do not form on some areas between the middle of the scratch and both corners. This process continues until the free zinc within the throwing power distance of the scratch is consumed, which is the point that the primer starts losing sacrificial protection action, i.e. $96 \mathrm{~h}$ in this study.

In addition, Fig. 3(k) shows the paint on the unscratched 1,000 h sample has not been delaminated. This indicates a good protection of the substrate. 

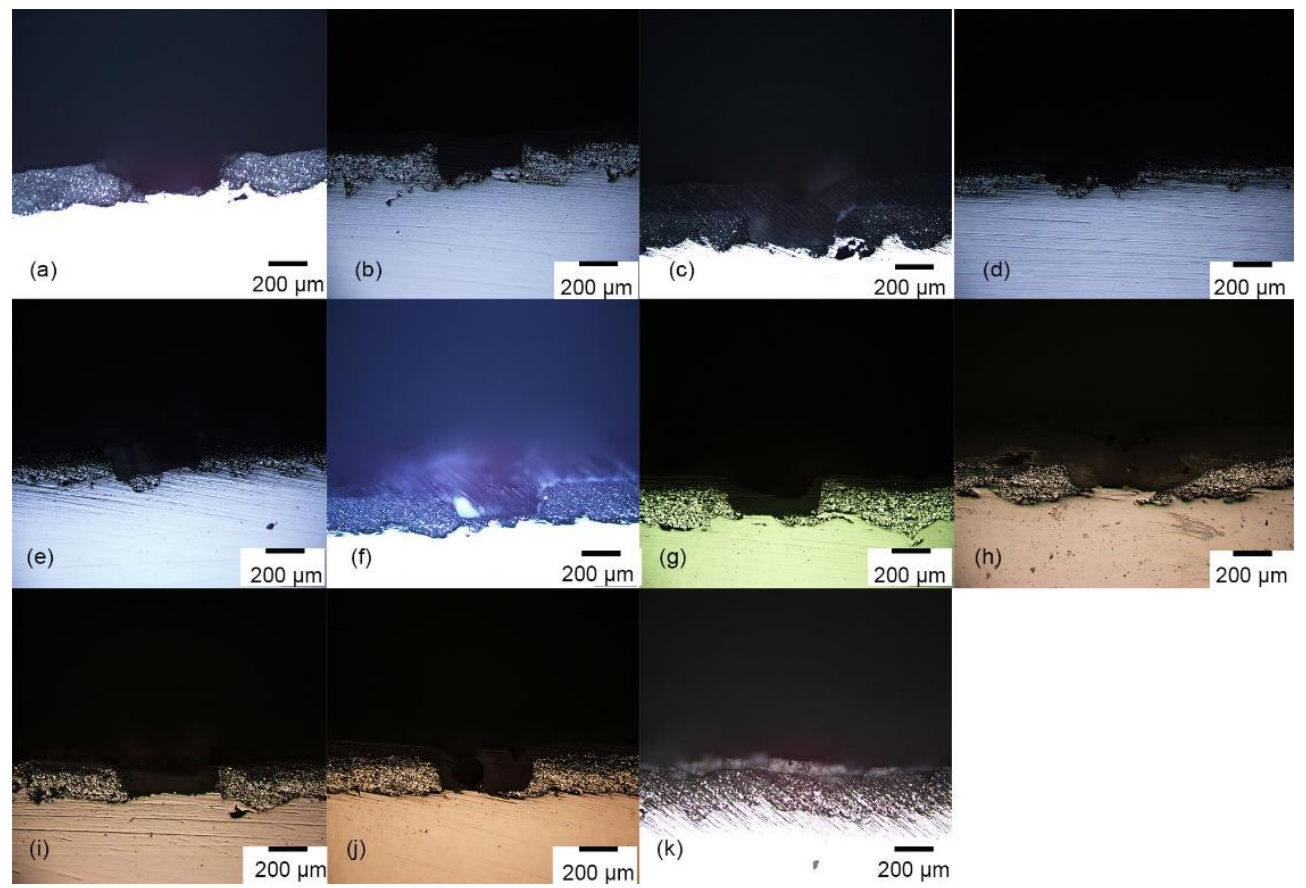

Fig. 3. Optical images obtained from cross sectional view of (a) 2, (b) 6 (c) 24 (d) 48, (e) 96, (f) 168, (g) 240, (h) 480, (i) 720, (j) 1,000, and (k) 1,000 unscratched hours exposed in salt fog chamber. The white arrows show the positions of porosity or cracks in the corrosion products.

SEM cross sectional images of the samples are depicted in Fig. 4. By comparing Fig. 3(a) to (k), the following mechanism would be proposed:

i) Zinc corrosion products precipitate immediately or up to $2 \mathrm{~h}$ since zinc gets corroded galvanically to protect the substrate. But for now, corrosion products cannot adhere to the iron substrate as they are porous (Figs. 4(a) and 4(c)) and/or contain crack (Fig. 4(b)). Hence, during 24 h, the corrosion products form in the scratch region and flake/detach subsequently. If the corrosion products detach and drag away from the substrate (for e.g. by electrolyte motion), free zinc will corrode to continue protection of the substrate galvanically.

ii) From $48 \mathrm{~h}$ to $96 \mathrm{~h}$ salt fog, compaction of the corrosion products happens as they contain less porosity (Figs. 4(d) and 4(e)). ZnO is the first corrosion product that compactly forms [19, 20]. As in this stage, the dense corrosion products are formed the active corrosion protection mechanism is barrier action.

iii) After $168 \mathrm{~h}$ of salt fog exposure, the barrier protection is less in action as the corrosive electrolyte has penetrated in the oxide layer, for instance by osmotic action mechanism. The results in production of porous corrosion products again which they detach from the surface (Fig. 4(f)). This means the system has returned to stage i. After some time, compaction of the corrosion products again occurs (Fig. 4(g)).

iv) This cycling between periods of formation of protective corrosion products and their subsequent detachment continues for the remainder of the exposure time (Figs. 4(h) to 4(j)).

Finally, Fig. 4(k) shows that the unscratched primer yet have adhesion to the substrate after 1,000 h salt fog. Voids were seen in the paint structure for the unscratched sample exposed for 1,000 h. But, the void density of the fresh un-corroded sample in Fig. 4(l) is less. Hence, more barrier protection will be given as the voids in the primer structure are being filled with zinc corrosion products. To confirm whether the iron substrate has been corroded after 1,000 h, Energy-dispersive X-ray spectroscopy (EDX) images of iron for the unexposed sample and for the 1,000 h exposed unscratched sample are shown in Figs. 5(a) and 5(b), respectively. Both Figs. 5(a) and 5(b) only show the iron distribution in the paint. Figure 5(b) reveals that 
the substrate has not been corroded after 1,000 $\mathrm{h}$ because iron element has not accumulated at anywhere close to substrate (Fig. 5(b)).

It is thus proposed that protection mechanism of the studied zinc rich primer might not be a sacrificial action followed by a barrier action, but an iteration of these two mechanisms; until either zinc content or throwing power is restricted. Eventually, iron corrosion products will become dominant, that is to say the paint adjacent to the scratch is no longer protective.

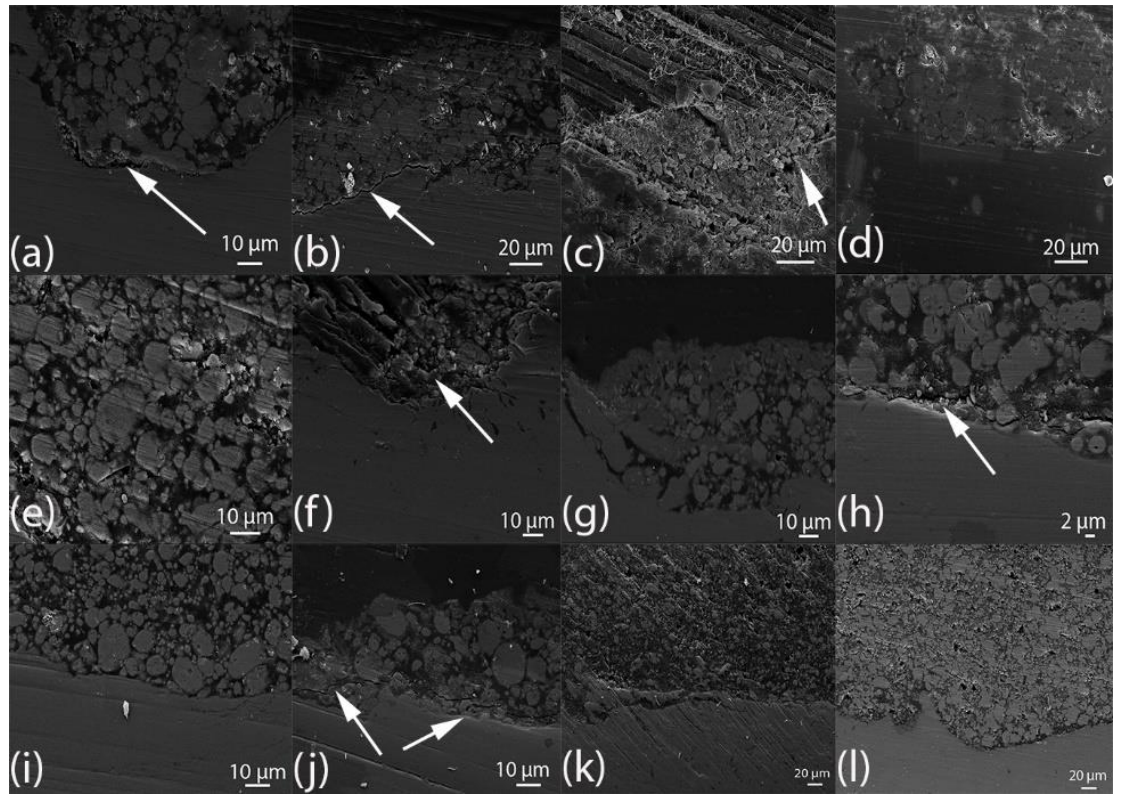

Fig. 4. Cross sectional SEM images for (a) 2, (b) 6, (c) 24, (d) 48, (e) 96, (f) 168, (g) 240, (h) 480, (i) 720, (j) 1,000, (k) 1,000 unscratched hours exposed in salt fog chamber. Also, (l) $0 \mathrm{~h}$ unscratched sample. The accelerating voltages are $15 \mathrm{kV}$ for a, b, d, h, j, k, and $20 \mathrm{kV}$ for the rest.
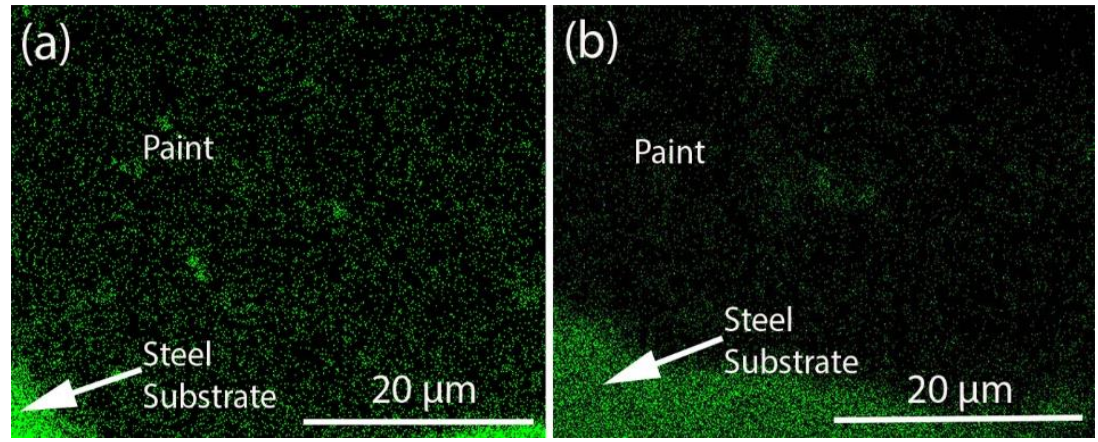

Fig. 5. The EDX maps of iron for (a) $0 \mathrm{~h}$ and (b) 1,000 $\mathrm{h}$ unscratched samples with $20 \mathrm{kV}$ accelerating voltage.

\subsection{Electrochemical Studies}

To further study the corrosion protection mechanism, some electrochemical measurements were conducted as follows.

\subsubsection{Open circuit potential (OCP)}

To make sure sacrificial protection is effective, NACE RP-01-69 Standard is being used. This criterion says that sufficient protection is attained while the cathodic potential is at least $-0.78 \mathrm{~V}$ (vs. SCE). Hence, ZRP may not adequately protect the substrate if the potential is less negative than $-0.780 \mathrm{~V}$ (vs. SCE). 
Figure 6 depicts the OCP of some of the samples collected within $500 \mathrm{~s}$ in salt solution with $3.5 \mathrm{wt} \%$ $\mathrm{NaCl}$. The beginning and ending values of OCP all of the samples are reported in Table 2. To compare, OCP of a scratched and an unscratched sample were measured for comparison. It is evident that OCP of exposed samples exposed up to $240 \mathrm{~h}$ are below $-0.78 \mathrm{~V}$, indicating sacrificial protection is well provided.

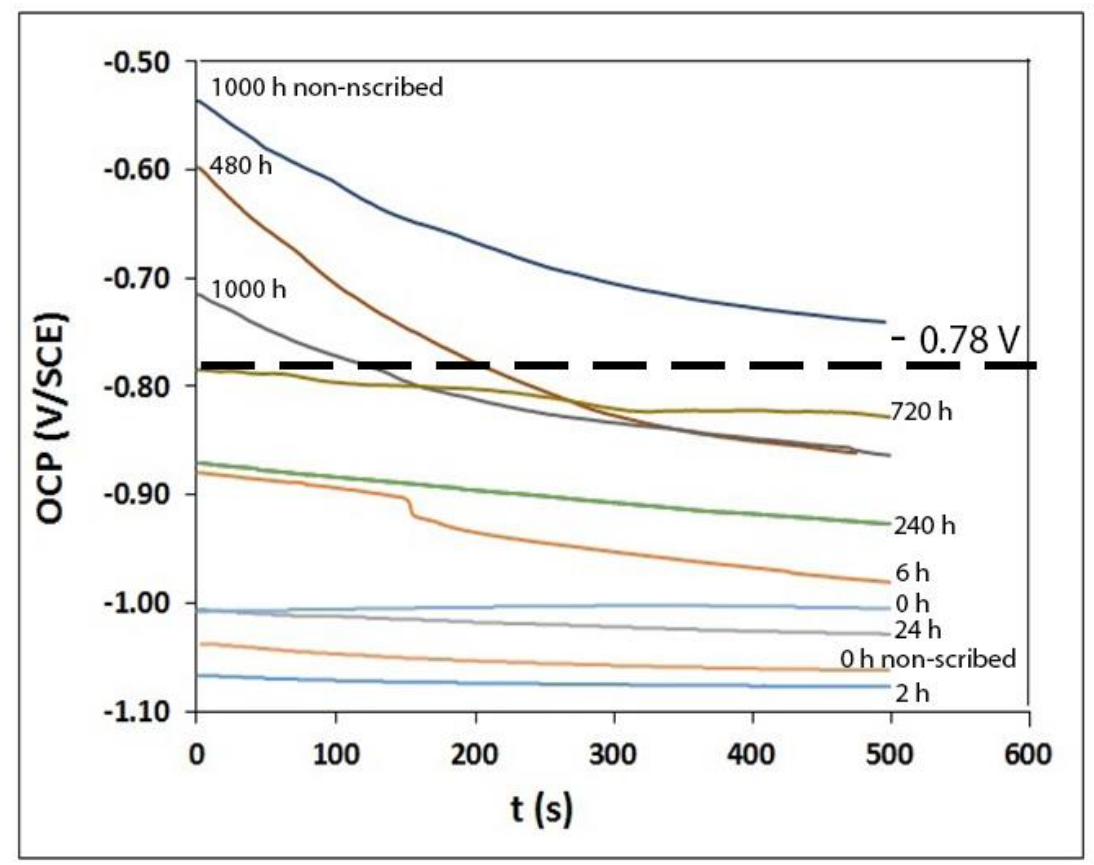

Fig. 6. OCP curves for some of the selected samples.

OCP values for $0 \mathrm{~h}$ scratched and unscratched samples can be read as -1.01 and $-1.06 \mathrm{~V}$, respectively. Because these samples had high dope of zinc pigment, their starting potential was ruled by potentials very close to zinc potential. The slight more positive value of OCP for $0 \mathrm{~h}$ scratched sample is due to exposure of some area of iron. But because the anode to cathode ratio is very large (60:1), the shift in OCP is very small.

The OCP for the $2 \mathrm{~h}$ scratched sample is $-1.08 \mathrm{~V}$ which is the most negative value because the electrolyte has wetted the ZRP well hence more amount of zinc corrodes compared to the $0 \mathrm{~h}$ samples.

Table 2 reports that the initial OCP of $6 \mathrm{~h}$ scratched sample was less negative $(-0.88 \mathrm{~V}$ vs. SCE) than the $2 \mathrm{~h}$ scratched sample, but $6 \mathrm{~h}$ sample is still in the protection zone. OCP value fort $6 \mathrm{~h}$ sample notably dropped after $500 \mathrm{~s}$. This could be due to the fact that more free zinc particles corroded galvanically.

Remark, for sacrificial protection, besides proper contact between zinc and substrate, the sidelong space is influential. If the lateral distance is very large, IR-drop will impede protection. Hence, employment of OCP to confirm if sacrificial protection exists could be deceptive for ZRPs if the iron to zinc ratio is very small. In such case OCP is dominated by zinc potential which is less than $-0.78 \mathrm{~V}$ (vs. SCE) whereas sacrificial protection might not be active. This could be the case for the samples from $24 \mathrm{~h}$ to $240 \mathrm{~h}$. Therefore, although their OCP are below $-0.78 \mathrm{~V}$ (vs. SCE), the active mechanism is most likely both sacrificial and barrier action because not only zinc particles could participate in sacrificial action, but also deposited corrosion products could provide barrier action. Hence, OCP being $-0.78 \mathrm{~V}$ criterion should be considered as a direction but not as a statement of fact. Accordingly, OCP values above $-0.78 \mathrm{~V}$ do not imply only barrier protection is in action, because iron corrosion products were observed in the scratch region for 480, 720, and 1000 hours samples whereas their OCPs are above or very close to $-0.78 \mathrm{~V}$ (vs. SCE).

Finally, OCP for the unscratched sample that has been exposed for $1,000 \mathrm{~h}$ was well above $-0.78 \mathrm{~V}$, whereas the OCP of $0 \mathrm{~h}$ unscratched sample was at $-1.06 \mathrm{~V}$. This shows that during 1,000 $\mathrm{h}$ exposure, the pores in the ZRP are filled/blocked with zinc corrosion products adequate corrosion products which results in excellent barrier protection. 
Table 2. The OCP and low frequency impedance values of the samples extracted from Figs. 6 and 7.

\begin{tabular}{llllll}
\hline $\begin{array}{l}\text { Sample } \\
\text { Condition }\end{array}$ & $\begin{array}{l}\text { Exposure } \\
\text { hours }\end{array}$ & $\begin{array}{l}\text { Initial } \\
\text { OCP } \\
\text { V (vs. SCE) }\end{array}$ & $\begin{array}{l}\text { Final } \\
\text { OCP } \\
\text { V (vs. SCE) }\end{array}$ & $\begin{array}{l}\text { Low- } \\
\text { Frequency } \\
\text { Impedance } \\
\mathbf{\Omega}\end{array}$ & $\begin{array}{l}\text { Test } \\
\text { Media }\end{array}$ \\
\hline \multirow{5}{*}{ Scratched } & 0 & -1.01 & -1.01 & 26 & $\begin{array}{l}\text { Fresh } \\
\text { sample }\end{array}$ \\
\cline { 2 - 6 } & 2 & -1.07 & -1.08 & 130 & Salt Spray \\
\cline { 2 - 6 } & 6 & -0.88 & -1 & 139 & Salt Spray \\
\cline { 2 - 6 } & 24 & -1.01 & -1.03 & 140 & Salt Spray \\
\cline { 2 - 6 } & 48 & -1.04 & -1.04 & 161 & Salt Spray \\
\cline { 2 - 6 } & 168 & -0.99 & -1 & 302 & Salt Spray \\
\cline { 2 - 6 } & 240 & -1.01 & -1.01 & 311 & Salt Spray \\
\cline { 2 - 6 } & 480 & -0.87 & -0.94 & 304 & Salt Spray \\
\cline { 2 - 6 } & 720 & -0.6 & -0.86 & 537 & Salt Spray \\
\cline { 2 - 6 } & 1000 & -0.71 & -0.86 & 715 & Salt Spray \\
\hline \multirow{3}{*}{ unscratched } & 1000 & -0.54 & -0.74 & 916 & Salt Spray \\
\cline { 2 - 6 } & 0 & -1.04 & -1.06 & 26 & $\begin{array}{l}\text { Fresh } \\
\text { Sample }\end{array}$ \\
\hline
\end{tabular}

\subsubsection{EIS}

Figure 7(a) shows the Bode plot of EIS technique for the selected samples. It should be noted that for zinc rich primers with the more than $70 \mathrm{wt} \%$ of zinc, fitting the EIS data is almost impossible as such coatings are highly conductive. This matter was also observed previously [4]. Therefore, as the impedance at the low-frequency data represents the total resistance of the system, such data were used to compare the relative corrosion resistance. As such, the low frequency impedance reported in Table 2 indicates the degree of protection of the ZRPs at various times. The values are in $\Omega$, instead of $\Omega . \mathrm{cm}^{2}$, because the impedance of the coating and the scratch could not be distinguished. At any rate, the impedance values could be multiplied by the area, $3 \mathrm{~cm}^{2}$, to obtain the values in $\Omega . \mathrm{cm}^{2}$.

Figure 7(b) shows the values of impedance at $0.1 \mathrm{~Hz}$ which is the minimum frequency. It can be seen that the $2 \mathrm{~h}$ exposed sample has $130 \Omega$ impedance which is the lowest value for all of the samples. On top, its OCP value is $-1.08 \mathrm{~V}$ which is the most negative. Both together indicate swift corrosion of the zinc which is akin to sacrificial protection. Correspondingly, the 1,000 $\mathrm{h}$ unscratched sample shows the highest low-frequency impedance value of $916 \Omega$ along with the most positive OCP value of $-0.74 \mathrm{~V}$ (vs. SCE). This indicates that zinc corrosion products have formed a barrier layer in the paint structure. Another evidence for this, would be the absence of iron corrosion products in this sample (Fig. 5). As a result, within the $1,000 \mathrm{~h}$ salt fog majority of the open voids have been filled with zinc corrosion products surrendering good barrier protection against corrosion of substrate.

The values of $130 \Omega$ and $916 \Omega$ for impedances at $0.1 \mathrm{~Hz}$ reveal two utmost impedance limits for this set of experiments, because the other exposed samples showed within this range. Figure 7(b) shows that the value of the impedances increase by salt fog exposure time. This could be related to the emergence of zinc corrosion products in the scratch region and the void spaces that increase the resistance as zinc corrosion products are insulating. Remark the low frequency impedance in Bode plot for most of the organic paints decrease by corrosion exposure time due to water uptake and degradation of the paint. Also, the low impedance values reported here compared to previous studies, for instance the values reported by Shreepathi et al. [4], are related to the higher zinc particles content of the paint in the current study (96 $\mathrm{wt} \%)$.

In addition, Fig. 7(b) shows two sharp leaps for impedance value increase: one from $48 \mathrm{~h}(161 \Omega)$ to 96 $\mathrm{h}(302 \Omega)$ and the other one from $240 \mathrm{~h}(304 \Omega)$ to 480 (537 $\Omega$ ). In conjunction with SEM images in Fig. 4, the presence of this steps is in relation with where the corrosion products have become compact and are 
without voids and cracks from 48 h to 96 h (Figs. 4(d) \& 4(e) with Figs. 4(a) to 4(c)). A similar justification can be given for the leap from $240 \mathrm{~h}$ to $480 \mathrm{~h}$. Note although a crack exists in the corrosion product layer at $480 \mathrm{~h}$ (Fig. 4(h)), this may not have been an open to electrolyte.
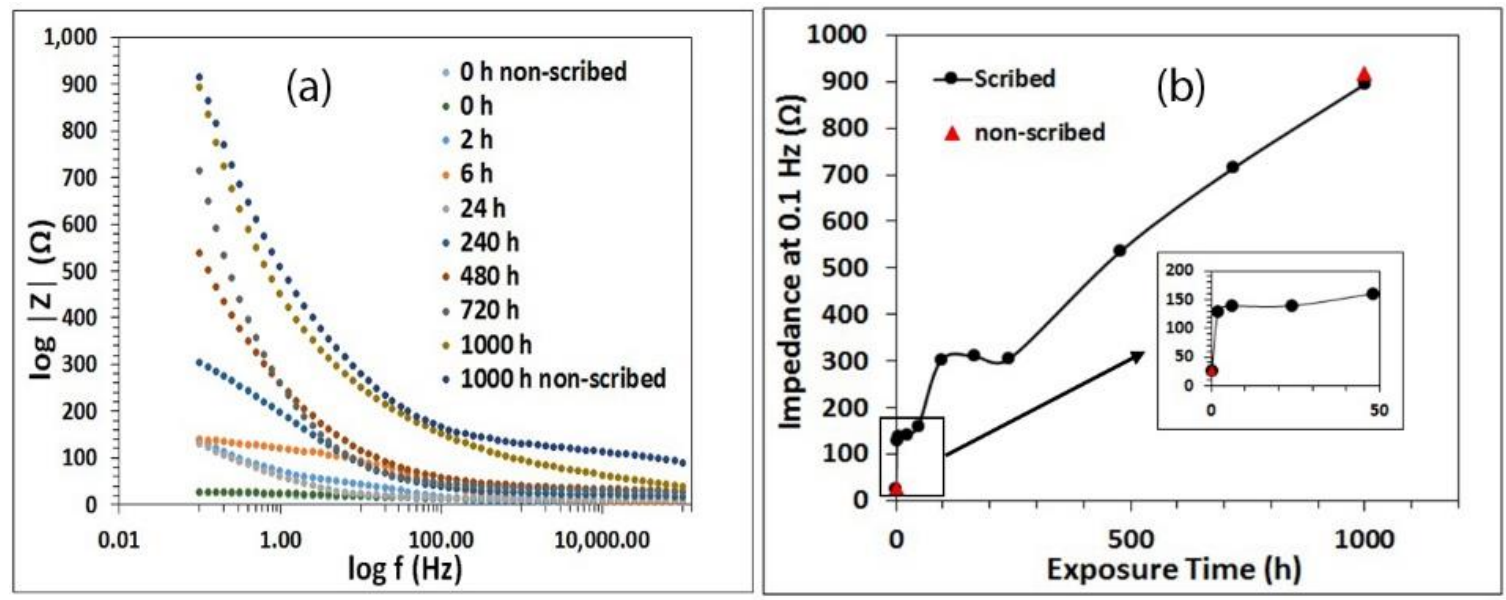

Fig. 7. (a) The Bode plot of the selected samples exposed to salt fog for up to 1,000 hours. (b) The value of the impedance of the samples which is extracted from Fig. 7(a) at $0.1 \mathrm{~Hz}$.

Altogether, the EIS results proposes that the mechanism of corrosion protection by ZRP may not be an only sacrificial protection period or an only barrier protection period; But it is a conjunction of the two mechanisms. However, only one of the mechanisms is dominated in each cycle. Remark, all of the available zinc corrodes, barrier action will become prevailing at extreme exposure times.

\section{Conclusion}

In this study, a specific type of zinc rich paint was applied on ASTM A36 steel substrate. The paint was scratched and exposed to salt fog test for up to 1,000 hours in accordance with ASTM B117. Formation of the corrosion products within the damaged region of the zinc paint was analyzed using microscopy and electrochemical techniques. The experimental results suggest that that mechanism of protection of the studied zinc rich paint is an iteration of sacrificial protection and barrier protection. Even though prior to deposition of zinc corrosion products in the scratch, sacrificial action is dominated, once the corrosion products start to form there is a conjunction of the two mechanisms with one mechanism prevailing from time to time.

\section{References}

[1] R. Jain and R. Pitchumani, "Fabrication and characterization of zinc-based superhydrophobic coatings," Surf. Coat. Technol., vol. 337, pp. 223-231, 2018.

[2] M. Saeedikhani, M. Javidi, and A. Yazdani, "Anodizing of 2024-T3 aluminum alloy in sulfuric-boricphosphoric acids and its corrosion behaviour," Trans. Nonferrous Met. Soc. China, vol. 23, no. 9, pp. 2551-2559, 2013.

[3] M. Saeedikhani, M. Javidi, and S. Vafakhah, "Anodising of 2024-T3 aluminium alloy in electrolyte of sulphuric- boric-phosphoric mixed acid containing cerium salt as corrosion inhibitor," Trans. Nonferrous Met. Soc. China, vol. 27, no. 3, pp. 711-721, 2017.

[4] S. Shreepathi, P. Bajaj, and B. P. Mallik, "Electrochemical impedance spectroscopy investigations of epoxy zinc rich coatings: Role of Zn content on corrosion protection mechanism," Electrochim. Acta, vol. 55, pp. 5129-5134, 2010.

[5] H. Marchebois, S. Joiret, C. Savall, J. Bernard, and S. Touzain, "Characterization of zinc-rich powder coatings by EIS and Raman spectroscopy," Surf. Coat. Technol., vol. 157 pp. 151-161, 2002.

[6] E. Diler, S. Rioual, B. Lescop, D. Thierry, and B. Rouvellou, "Chemistry of corrosion products of Zn and MgZn pure phases under atmospheric conditions," Corros. Sci., vol. 65, pp. 178-186, 2012. 
[7] E. Diler, B. Rouvellou, S. Rioual, B. Lescop, G. Nguyen Vien, and D. Thierry, "Characterization of corrosion products of $\mathrm{Zn}$ and $\mathrm{Zn}-\mathrm{Mg}-\mathrm{Al}$ coated steel in a marine atmosphere," Corros. Sci., vol. 87 pp. 111-117, 2014.

[8] M. C. Bernard, A. Hugot-Le Goff, D. Massinon, and N. Phillips, "Underpaint corrosion of zinccoated steel sheet studied by in situ Raman spectroscopy," Corros. Sci., vol. 35, pp. 1339-1349, 1995.

[9] T. Ohtsuka, and M. Matsuda, "In situ Raman spectroscopy for corrosion products of zinc in humidified atmosphere in the presence of sodium chloride precipitate," Corrosion, vol. 59, pp. 407-413, 2003.

[10] A. H.-L. Goff, S. Joiret, B. Saïdani, and R. Wiart, "In-situ Raman spectroscopy applied to the study of the deposition and passivation of zinc in alkaline electrolytes," J. Electroanal. Chem. Interfacial Electrochem., vol. 263, pp. 127-135, 1989.

[11] M. Ghaffari, M.R. Saeb, B. Ramezanzadeh, and P. Taheri, "Demonstration of epoxy/carbon steel interfacial delamination behaviour: Electrochemical impedance and X-ray spectroscopic analyses," Corros. Sci., vol. 102, pp. 326-337, 2016.

[12] F. Mahdavi, M. Forsyth, and M. Y. J. Tan, "Techniques for testing and monitoring the cathodic disbondment of organic coatings: An overview of major obstacles and innovations," Prog. Org. Coat., vol. 105, pp. 163-175, 2017.

[13] F. Mahdavi, M. Y. J. Tan, and M. Forsyth, "Electrochemical impedance spectroscopy as a tool to measure cathodic disbondment on coated steel surfaces: Capabilities and limitations," Prog. Org. Coat., vol. 88, pp. 23-31, 2015.

[14] B. Hirschorn, M. E. Orazem, B. Tribollet, V. Vivier, I. Frateur, and M. Musiani, "Determination of effective capacitance and film thickness from constant-phaseelement parameters," Electrochim. Acta, vol. 55, pp. 6218-6227, 2010.

[15] M. Saeedikhani, S. Wijesinghe, and D. Blackwood, "Revisiting corrosion protection mechanisms of steel surface by damaged zinc rich paints," Corrosion, vol. 75, no. 7, pp. 756-770, 2019.

[16] C. M. Abreu, M. Izquierdo, M. Keddam, X. R. Nóvoa, and H. Takenouti, "Electrochemical behaviour of zinc-rich epoxy paints in 3\% NaCl solution," Electrochim. Acta, vol. 41, pp. 2405-2415, 1996.

[17] H. Marchebois, C. Savall, J. Bernard, and S. Touzain, "Electrochemical behavior of zinc-rich powder coatings in artificial sea water," Electrocbim. Acta, vol. 49, pp. 2945-2954, 2004.

[18] F. Mansfeld, H. Shih, H. Greene, and C. H. Tsai, Electrochemical Impedance: Analysis and Interpretation, ASTM STP 1181, J. Scully, D. C. Silverman, and M. Kendig, Eds. Philadelphia, PA: ATSM, 1993, p. 37.

[19] S. Thomas, I. S. Cole, M. Sridhar, and N. Birbilis, "Revisiting zinc passivation in alkaline solutions," Electrochim. Acta, vol. 97, 192-201, 2013.

[20] S. Thomas, I. S. Cole, Y. Gonzalez-Garcia, M. Chen, M. Musameh, J. M. C. Mol, H. Terryn, and N. Birbilis, "Oxygen consumption upon electrochemically polarised zinc," J. Appl. Electrochem., vol. 44, pp. 747-757, 2014.

[21] A. Amirudin and D. Thierry, "Corrosion mechanisms of phosphated zinc layers on steel as substrates for automotive coatings," Prog. Org. Coatings., vol. 28, pp. 59-76, 1996. 